\title{
Evolução espaço-temporal do uso do solo na Estação Ecológica do Rangedor e seu entorno
}

A criação de Unidades de Conservação (UC) representa um instrumento essencial para a conservação de ambientes naturais, principalmente nas regiões metropolitanas, como é o caso da Estação Ecológica do Rangedor - ESEC, caracterizada como unidade de Proteção Integral que permite somente o uso indireto dos recursos naturais. Neste trabalho aborda-se a evolução espaço-temporal do uso da terra da ESEC do Rangedor e seu entorno (1 km), nos anos de 1976, 2001 e 2012, a fim de analisar a dinâmica das mudanças espaço-temporais e se a UC está sendo efetiva na sua função ecológica. Com este propósito, utilizaram-se as ferramentas de geoprocessamento e sensoriamento remoto, além de expedições de campo, visando compreender a dinâmica dos impactos ambientais no comprometimento dos habitats e componentes ecológicos da área protegida e os aspectos geoambientais e socioeconômicos que permeiam a problemática hídrica na Estação Ecológica do Rangedor Constatou-se que houve uma expressiva redução da drenagem na área protegida, além da ocorrência de outros impactos como desmatamento, invasão de espécies alóctones, queimadas e deposição de resíduos sólidos, que comprometem os atributos e o enquadramento da unidade de conservação na categoria de proteção integral. Por outro lado, apesar de todos os problemas ambientais observados neste estudo, a existência da ESEC oferece a possibilidade de recuperação da vegetação natural e atua efetivamente contra a ameaça de expansão imobiliária para o interior da área protegida.

Palavras-chave: Geoprocessamento; Unidade de Conservação; Uso da Terra; Expansão Urbana.

\section{Spatial and temporal evolution of land-use in the Rangedor Ecological Station and its surrounding}

\begin{abstract}
The creation of Conservation Units (CU) is an essential tool for the conservation of natural environments, especially in the metropolitan areas, as is the case of the Rangedor Ecological Station - ESEC, characterized as unit of integral protection that allows only the indirect use of natural resources. This paper deals with the spatial and temporal patterns of use of the land in the ESEC of Rangedor and its surrounding area (1 km), in the years 1976, 2001 and 2012, in order to analyze the dynamics of spatial-temporal changes and if the UC is being effective in its ecological function. For this purpose, we used the geoprocessing and remote sensing tools, as well as survey of field, aiming to understand the dynamics of environmental impacts in the impairment of habitats and ecological components of the protected area and the geoenvironmental aspects and socioeconomic variables that permeate the water problem in the Rangedor Ecological Station. It was found that there was a significant reduction of drainage in the protected area, in addition to the occurrence of other impacts such as deforestation, invasion of alien species, burned and solid waste disposal, which compromises the attributes and the framework of conservation unit in the category of integral protection. On the other hand, in spite of all the environmental problems observed in this study, the existence of the ESEC offers the possibility of recovery of the natural vegetation and acts effectively against the threat of building for the inside protected area.
\end{abstract}

Keywords: Geoprocessing; Conservation Units; Land-use; Urban Expansion.

\section{Topic: Sistemas de Gestão Ambiental}

Reviewed anonymously in the process of blind peer.

Rosângela Borges Almeida

Universidade Federal do Maranhão, Brasi

http://lattes.cnpq.br/1385969678506335

almeida_rb@hotmail.com

Antônio Carlos Leal de Castro

Universidade de São Paulo, Brasil

http://lattes.cnpq.br/9450410023114396

alec@ufma.br

\section{Gisele Cardoso de Araújo}

Universidade Federal do Maranhão, Brasil

http://lattes.cnpq.br/1961481517625471

gisacardoso@hotmail.com

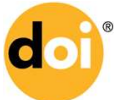

DOI: 10.6008/SPC2179-6858.2017.003.0022
Received: $14 / 03 / 2017$

Approved: 15/05/2017

\author{
Leonardo Silva Soares \\ Universidade Federal do Piauí, Brasil \\ http://lattes.cnpq.br/5352983119262178 \\ leonardoufma@yahoo.com.br
}

Referencing this:

ALMEIDA, R. B.; CASTRO, A. C. L.; ARAÚJO, G. C.; SOARES, L. S.. Evolução espaço-temporal do uso do solo na estação ecológica do rangedor e seu entorno. Revista Ibero-Americana de Ciências Ambientais, v.8, n.3, p.238-253, 2017. DOI: http://doi.org/10.6008/SPC2179-6858.2017.003.0022 


\section{INTRODUÇÃO}

A compreensão da importância da conservação e manejo de áreas naturais, bem como da integridade dos ecossistemas e de seus processos ecológicos essenciais, são instrumentos importantes para se atingir a sustentabilidade desses ambientes. A ação antrópica representa um relevante agente modificador ambiental, alterando o equilíbrio e a dinâmica dos processos naturais, gerando novas funções e criando mosaicos estreitamente relacionados com as práticas culturais e o desenvolvimento de uma região (TORRES-GÓMEZ, 2009). Esta situação pode ser observada frequentemente nas regiões metropolitanas das cidades brasileiras.

A partir da década de 70, a região metropolitana de São Luís começou a sofrer um acelerado crescimento populacional, devido ao advento de grandes empreendimentos industriais, a demanda por moradias e infraestrutura, além da ocupação irregular próxima aos cursos d'água. As formas como ocorreram a ocupação do espaço urbano tem provocado sucessivos e inúmeros problemas ambientais, como a degradação da cobertura vegetal, perda da biodiversidade, obstrução e alteração da rede de drenagem, acúmulo de lixo, contaminação de solo e água, poluição do ar, água e solo, perda de terras produtivas, desencadeamento de processos erosivos, entre tantos outros impactos de natureza ambiental.

A expansão de áreas urbanas, as atividades de construção de obras civis, o incremento de áreas agrícolas e pastoris, entre outras atividades desenvolvidas pelas sociedades ao longo dos séculos, vêm alcançando estágios de desenvolvimento, eficiência e domínio tecnológico que, na maioria das vezes, não são acompanhados do processo de organização e planejamento, necessários para a sustentabilidade da natureza (GUERRA et al., 2006).

Como resultado das ações antrópicas, a estrutura e funcionamento dos ecossistemas mudaram rapidamente nas últimas décadas. A magnitude dessas mudanças acompanha o crescimento da população e o aumento da intensidade da atividade econômica. A pressão das atividades humanas, representadas pela intensidade do uso do solo sobre os ecossistemas naturais, determinam impactos na biodiversidade decorrentes da perda de habitats e mudanças na qualidade da paisagem (SANTOS, 2011). O ordenamento territorial da paisagem, associado à criação de áreas protegidas, compreende uma das formas para se garantir a conservação destes recursos naturais, normatizando qualquer intervenção, com vistas a manter sua integridade, vinculada aos usos que lhe são pertinentes.

Nesse contexto, foi criada a Estação Ecológica do Rangedor (ESEC), localizada na região urbana do município de São Luís, em uma área extremamente valorizada economicamente. Esta Unidade de Conservação (UC), enquadrada na categoria de Proteção Integral, constitui um importante espaço de recarga natural que contribui para o suprimento da demanda de água subterrânea, manutenção do regime de perenização de alguns rios, equilíbrio da paisagem e regulação térmica de um conjunto de bairros nobres situados no seu entorno.

Com este propósito, busca-se analisar a evolução da paisagem da Estação Ecológica do Rangedor e seu entorno, objetivando identificar os principais tensores ambientais associados às mudanças espacial $\mathrm{e}$ 
temporal dos usos e ocupação do solo, para compreender a dinâmica dos distúrbios antrópicos no comprometimento dos habitats e componentes ecológicos da área protegida.

\section{MATERIAIS E MÉTODOS}

\section{Área de estudo}

A área de estudo está inserida na llha do Maranhão $\left(02^{\circ} 24^{\prime} 10^{\prime \prime}-02^{\circ} 46^{\prime} 37^{\prime \prime} \mathrm{S}\right.$ e $44^{\circ} 22^{\prime} 39^{\prime \prime}-44^{\circ} 22^{\prime}$ 39" W), mais especificamente no município de São Luís e compreende a Estação Ecológica do Rangedor, mais o seu entorno equivalente a um raio de $1 \mathrm{~km}$ em torno do perímetro da área protegida, ilustrada na figura 1. A ESEC do Rangedor encontra-se sujeita, assim como a cidade de São Luís, à influência da massa de ar Equatorial Marítima e da convergência dos ventos alísios do Nordeste e Sudeste. O clima é tropical chuvoso, com estação seca de inverno, tipo Aw, conforme a classificação de Köppen. A sazonalidade da chuva na área é marcante, indicando o período chuvoso de janeiro a junho, e o período seco de julho a dezembro com pluviosidade média anual de $1.857,16 \mathrm{~mm}$, temperatura de $27^{\circ} \mathrm{C}$ e uma umidade de $80 \%$ (PEREIRA, 2008).

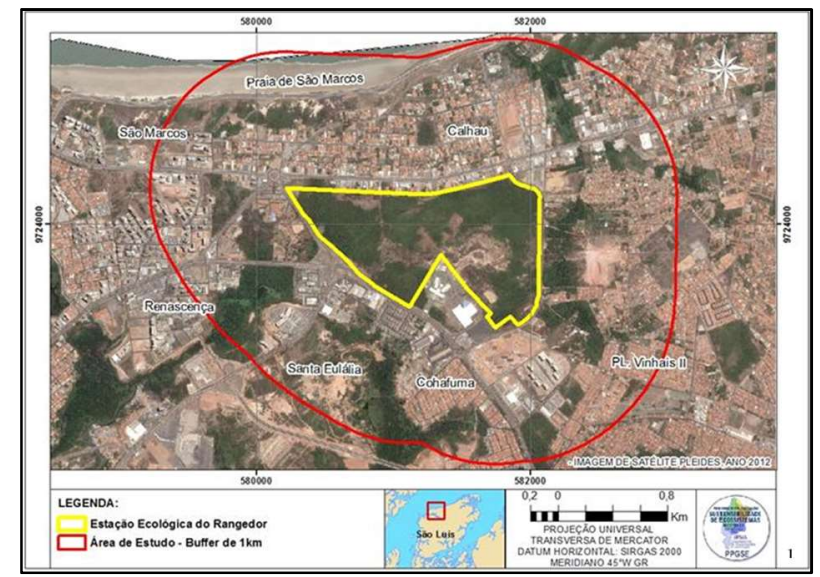

Figura 1: Localização da Estação Ecológica do Rangedor - São Luís/MA.

Estação Ecológica do Rangedor compreende uma área de 120,95ha e perímetro de 5.569,90 metros. Limita-se ao norte com a Rua dos Búzios, no bairro do Calhau; a leste com o Ginásio Raimundo Sá e Avenida Eduardo Magalhães; ao sul com a Avenida Jerônimo de Albuquerque; e a oeste com a Avenida General Euclides Figueiredo.

Conforme a Lei de Zoneamento Municipal, essa ESEC está localizada em Corredor Primário de múltiplos usos e primeiro eixo de expansão da cidade. A categoria de proteção integral da área foi proposta por esta apresentar propriedades geotécnicas e pedológicas, com características fisiográficas locais de importante relevância para o processo de infiltração de águas pluviais. Essas características tornam o Sítio do Rangedor uma área de recarga de aquíferos, interagindo com a dinâmica das águas da microbacia do rio Calhau e com a sub-bacia do Rio Anil.

\section{Procedimentos Metodológicos}

Para a ESEC, especificamente, foi analisado seu plano de manejo e sua legislação específica. Além disso, foi realizada visitas à SEMA para o levantamento de informações referentes à situação atual dessa UC. 
A etapa de campo foi realizada através de cinco expedições na ESEC do Rangedor, distribuídas no período de setembro de 2013 a março de 2014, com objetivo de realizar o reconhecimento da área, a localização de seus limites e a identificação de alguns tensores ambientais. $O$ registro do local foi efetuado com auxílio de GPS (calibrado para o sistema de projeção UTM, Datum horizontal SIRGAS 2000) e fotografias.

Para trabalhar os dados espaciais, utilizou-se o Sistema de Informação Geográfica SPRING ver. 5.2, no qual foi estruturado o banco de dados e adotado o sistema de coordenadas planas, projeção UTM, Datum SIRGAS 2000, na escala 1:25.000. Posteriormente, foram definidos os modelos de dados a serem trabalhados: temático, numérico e imagem, que permitiram a entrada dos arquivos digitais ao banco para execução dos procedimentos de análise ambiental. O quantitativo da população residente do entorno da ESEC, no raio de $1 \mathrm{~km}$, foi extraído da base de dados dos censos demográficos do IBGE de 2000 e 2010. A população residente foi estimada pelos moradores em domicílios na data de referência (IBGE, 2000; 2010).

\section{Delimitação da área de estudo}

Para construir a poligonal da ESEC foram utilizadas as demarcações disponíveis no Decreto Estadual no 23.303 de 07 de agosto de 2007, que redefine os limites da Estação Ecológica Rangedor. A ESEC do Rangedor não possui uma zona de amortecimento definida no seu plano de manejo. Essa zona de amortecimento corresponde ao entorno de uma unidade de conservação, onde as atividades humanas estão sujeitas a normas e restrições específicas, com o propósito de minimizar os impactos negativos sobre a Unidade de Conservação (Brasil, 2000). Para efeito deste estudo delimitou-se, um raio de $1 \mathrm{~km}$ equidistante da UC. Optou-se por essa distância pelo fato dessa Estação Ecológica está localizada em uma área urbana bem consolidada.

\section{Análise da evolução do uso e cobertura do solo da ESEC e seu entorno nos anos de 1976, 2001 e 2012}

Para analisar a evolução espaço-temporal do uso e cobertura do solo, foram utilizadas as imagens aéreas de alta resolução para os anos de 1976, 2001 e 2012. Estas não seguem uma ordem cronológica sistemática porque são as imagens disponíveis com essa resolução para a área de estudo, considerando um cenário mais antigo, outro antes da implantação da UC (2005) e um cenário mais recente.

A análise dessa evolução foi sustentada pela construção de três planos de informações no SPRING 5.2, um para cada ano a ser estudado. Em seguida, foram definidas as classes temáticas a partir da interpretação visual e representatividade na escala de mapeamento adotada. Após essa etapa foi feita a vetorização dos polígonos e em seguida iniciou-se o processo de topologia e associação das classes aos mesmos.

Para evidenciar a dinâmica de substituição de classes e indicar alguns fatores de pressão antrópica como, por exemplo, o crescimento urbano e o desmatamento, as imagens foram classificadas em treze classes e posteriormente comparadas para se obter a evolução do uso do solo entre os anos de 1976, 2001 e 2012, quantificando a variação ocorrida e indicando em que ambiente as mudanças ocorreram. 


\section{Comparação das mudanças na densidade de drenagem que corta a UC em 1980 e 2012}

Para esta análise foi construído um mapa de bacias hidrográficas, mostrando a inserção da ESEC nestas unidades básicas de planejamento dos recursos hídricos. Foi determinado também o padrão de drenagem com uso de cartas planialtiméricas da DSG, na escala 1:10.000 dos anos de 1980 e 2012. Estas cartas foram inseridas ao banco do modelo de dados temáticos, para viabilizar a vetorização da rede de drenagem da área e da zona de amortecimento (buffer de $1 \mathrm{~km}$ ). Posteriormente, realizou-se o cálculo da densidade de drenagem na área de estudo para cada ano, 1980 e 2012. A densidade de drenagem (Dd) corresponde à relação entre o comprimento total de rios da bacia $(\mathrm{Cr})$ e a área total da microbacia (A). $\mathrm{O}$ cálculo foi realizado segundo Horton (1945), pela equação $\mathrm{Dd}=\mathrm{Cr} / \mathrm{A}$, onde: $\mathrm{Dd}=$ densidade de drenagem em $\mathrm{km}$ de rios $/ \mathrm{km}^{2} ; \mathrm{Cr}=$ comprimento total de rios; e $\mathrm{A}=$ área da microbacia.

Segundo França (1968), a densidade de drenagem pode ser considerada baixa quando for menor que 1,5; média quando estiver no intervalo de 1,5 a 2,5; e alta quando for maior que 2,5. Considerou-se, neste trabalho, como a área da microbacia, a soma das áreas das bacias de pequeno porte inseridas na UC e no envoltório de $1 \mathrm{~km}$.

\section{Os principais tensores ambientais que ameaçam a ESEC do Rangedor}

A identificação dos principais tensores ambientais foi efetuada com o auxílio de um GPS e máquina digital. Foram coletados os pontos em áreas desmatadas, áreas ocupadas por resíduos sólidos e presença de espécies invasoras. Além disso, com o uso do geoprocessamento, foi elaborado um mapa de proximidade de estradas. O mapeamento da proximidade de estradas foi realizado com o uso do SPRING 5.2 utilizando imagem aérea, resolução espacial de $1 \mathrm{~m}$. A categoria utilizada no plano de informação foi o temático e depois foi feita a vetorização das estradas. Na elaboração do mapa foram adotadas as seguintes distâncias, em metros, em relação à UC: 100, 250, 500, 1000. Quanto menor essa distância, maior será a probabilidade de impacto sobre a ESEC do Rangedor.

\section{Avaliação da efetividade da Estação Ecológica do Rangedor}

Para avaliar a efetividade de conservação da ESEC do Rangedor, foram utilizadas as ferramentas do sensoriamento remoto e do geoprocessamento, além da observação direta durante as expedições de campo. Nesta avaliação, considerou-se o resultado das análises do uso e cobertura do solo da ESEC e seu entorno nos anos de 1976, 2001 e 2012, o padrão de mudanças na drenagem dos corpos d'água que cortam a UC, e o levantamento dos principais tensores que ameaçam a Unidade de Conservação.

\section{RESULTADOS E DISCUSSÃO}

\section{Delimitação da área de estudo}

Os bairros Calhau, Renascença, São Marcos e Cohafuma são considerados bairros de classes sociais com elevado poder aquisitivo e devido as suas proximidades com as praias são altamente valorizados, sendo grandes alvos da especulação imobiliária. Os imóveis construídos nessas áreas são enormes paredões que 
dificultam a circulação do ar, impermeabilizam o solo e são responsáveis por perdas significativas da vegetação, gerando assim um aumento considerável da temperatura para a área em questão. Atualmente, nas proximidades da Estação Ecológica do Rangedor estão sendo construídos vários imóveis verticais, inclusive o grande condomínio Jardins, no bairro do Cohafuma. O Entorno da ESEC do Rangedor, considerando uma zona de amortecimento de $1 \mathrm{~km}$ estabelecido para este estudo, compreendeu os bairros listados na Tabela 1.

Tabela 1: Localidades do entorno da ESEC do Rangedor em um raio de $1 \mathrm{~km}$.

\begin{tabular}{|l|l|}
\hline Alto do Calhau & Renascença \\
\hline Calhau & Santa Eulália \\
\hline Cohafuma & São Marcos \\
\hline Conjunto Hab. Vinhais & Vila Independente \\
\hline Planalto Vinhais I & Vinhais I \\
\hline Planalto Vinhais II & Vinhais II \\
\hline Praia de São Marcos & Vinhais III \\
\hline Quitandinha & \\
\hline
\end{tabular}

De acordo com Souza (2005), o bairro Renascença possui uma boa infraestrutura, possuindo água, luz, telefone e ônibus, sendo também valorizado pela proximidade de praias, bancos, hospitais, supermercados, shoppings, etc. Semelhantemente, todas as localidades que fazem parte do entorno da ESEC do Rangedor também gozam dessa infraestrutura. O sítio Santa Eulália é de grande importância, pois abriga uma zona de reserva florestal, definida no Plano Diretor de São Luís. Essa área protegida está localizada, praticamente, em frente à ESEC do Rangedor, separada apenas pela Avenida Jerônimo de Albuquerque.

Anterior à construção dessa via, as duas unidades formavam uma área contígua. Hoje, tenta-se conservar uma parte da vegetação e dos recursos hídricos nessa área com o estabelecimento de ações respaldadas na legislação vigente em áreas protegidas. No entanto, nota-se que por parte do poder público não há nenhum interesse em seguir a lei, pois o mesmo a descumpre através de várias construções dentro ou nas proximidades dessas áreas como, por exemplo, a construção da Assembleia Legislativa que suprimiu vegetação, nascentes e gerou uma série de outros impactos ambientais; e mais recentemente está sendo construído o INMEQ, no interior da ESEC.

Já o Sítio Santa Eulália tem como ameaça atual, a construção da Via Expressa de São Luís. As duas áreas protegidas foram criadas sem seguir o rigor da lei, pois não apresentam nem zona de amortecimento, o que inibiria de certa forma esse avanço da expansão urbana sobre os recursos naturais remanescentes. Baseado nos censos demográficos do IBGE de 2000 e 2010, o entorno da ESEC do Rangedor, em um espaço equidistante de $1 \mathrm{~km}$ do seu limite, vem apresentando um incremento populacional bastante expressivo. A população residente passou de 19.826 para 26.914. Paralelamente, o número de domicílios também aumentou, sendo que os particulares permanentes ampliaram de 5.020 para 7.970 , com as consequências advindas do aglomerado urbano.

\section{Análise da evolução do uso e cobertura do solo da ESEC e seu entorno nos anos de 1976, 2001 e 2012}

A análise de uso e cobertura do solo na UC durante o ano de 1976 revelou um predomínio da vegetação com uma superfície de $7,18 \mathrm{~km}^{2}(75,68 \%)$ do total de unidades de paisagem mapeadas (Tabela 2 ). 
Contrariamente, em 2012, houve uma drástica redução da vegetação, que resultou em uma cobertura de apenas $30,26 \%$, conforme se nota na figura 2 . Em contrapartida, a área urbanizada que corresponde a área construída, aumentou de $0,18 \mathrm{~km}^{2}(1,86 \%)$ para $5,16 \mathrm{~km}^{2}(54,43 \%)$ no período mapeado. Isso indica uma perda significativa de áreas verdes e consequentemente diminuição dos serviços ecossistêmicos como a regulação térmica, infiltração de água e controle de processos erosivos do solo.

Tabela 2: Uso e cobertura do solo da ESEC do Rangedor nos anos de 1976, 2001 e 2012.

\begin{tabular}{|c|c|c|c|}
\hline \multirow{2}{*}{ Classes } & 1976 & 2001 & 2012 \\
\hline & $\%\left(\mathrm{Km}^{2}\right)$ & $\%\left(\mathrm{Km}^{2}\right)$ & $\%\left(\mathrm{Km}^{2}\right)$ \\
\hline Área de urbanização alta & - & $40,95(3,88)$ & $52,54(4,98)$ \\
\hline Área de urbanização baixa & - & $3,16(0,30)$ & $1,78(0,17)$ \\
\hline Área de urbanização média & - & $0,60(0,06)$ & $0,11(0,01)$ \\
\hline Área Semiurbanizada & $1,86(0,18)$ & - & - \\
\hline Cultivo diversificado & - & - & $0,25(0,02)$ \\
\hline Região de dunas e restinga & $2,91(0,28)$ & $0,61(0,06)$ & $0,59(0,06)$ \\
\hline Região de loteamento & $10,54(1,00)$ & - & - \\
\hline Região de praia & $3,82(0,36)$ & $3,91(0,37)$ & $3,95(0,37)$ \\
\hline Solo exposto & $5,19(0,49)$ & $8,97(0,85)$ & $9,77(0,93)$ \\
\hline Vegetação aberta & - & $7,63(0,72)$ & $4,62(0,44)$ \\
\hline Vegetação densa & - & $22,65(2,15)$ & $19,39(1,84)$ \\
\hline Vegetação densa e aberta & $75,68(7,18)$ & - & - \\
\hline Vegetação rala & - & $11,53(1,09)$ & $6,25(0,59)$ \\
\hline
\end{tabular}

Em 2001 e 2012, a vegetação densa, que caracteriza uma área mais conservada apresenta uma superfície de 2,15 e 1,84km², respectivamente, correspondendo a $22,65 \%$ e $19,39 \%$ do total mapeado. Estes quantitativos são relativamente baixos e configuram uma tendência para as áreas urbanizadas. Entretanto, essa vegetação densa está concentrada, principalmente, na ESEC do Rangedor, aparecendo como uma mancha urbana, o que confirma a importância da UC na contribuição para o equilíbrio dos padrões climáticos, diminuindo assim os efeitos de ilha de calor sobre a capital. Portanto, a criação e definição desta UC na categoria de Proteção Integral serviram para inibir a supressão total da vegetação dessa área tão valorizada pela especulação imobiliária.

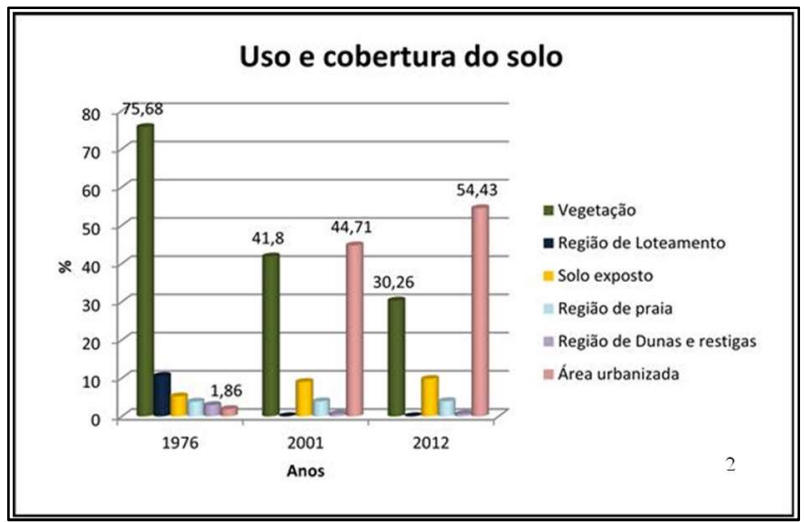

Figura 2: Uso e cobertura do solo nos anos de 1976, 2001 e $2012^{1}$.

O solo exposto, analisado no ano de 1976, representa uma pequena proporção da área total investigada, conforme a figura 2, e está mais concentrado na região central da ESEC do Rangedor. Em 2012,

\footnotetext{
${ }^{1}$ A Figura 2 é resultante das somas das classes que se repetem na Tabela 2. Assim, buscou-se concentrar as principais variáveis que podem influenciar na manutenção dos recursos hídricos e no controle climático da região, ou seja, a vegetação e a área urbanizada.
} 
sete anos após a implantação da UC, ainda se observa essa área exposta, o que pode ser atribuído ao seu histórico de jazida de cascalho e areia para a construção civil, muito embora já se encontra desativada há alguns anos. No momento, existe um projeto voltado para reflorestamento dessa área com espécies nativas.

Pereira (2008) destaca que a severa degradação das propriedades naturais de boa parte da superfície local da ESEC do Rangedor, por remoção das camadas superiores de solo, areias eluviais e arenito laterítico, durante a construção da Avenida Litorânea e Luís Eduardo Magalhães dinamizou a formação de crosta de arenização. Recentemente, a construção do prédio da Assembleia Legislativa do Estado do Maranhão, também restringiu o potencial de infiltração da área e dinamizou o processo erosivo.

\section{Comparação das mudanças na densidade de drenagem que atravessa a UC em 1980 e 2012}

A área de estudo está inserida em três bacias hidrográficas, conforme é exposto na tabela 3, sendo que essas bacias apresentadas não representam sua extensão total, ou seja, constitui apenas o segmento inserido na ESEC e seu entorno em um raio de $1 \mathrm{~km}$. Neste sentido, a maior parte da UC está localizada na bacia do Rio Calhau, seguida do Rio Anil.

Tabela 3: Bacias Hidrográficas presentes na área de estudo.

\begin{tabular}{|c|c|c|}
\hline Bacia & Perímetro $(\mathbf{K m})$ & Área $\left(\mathbf{K m}^{2}\right)$ \\
\hline Rio Calhau & 9,54 & 4,59 \\
\hline Costeira & 6,38 & 1,37 \\
\hline Rio Anil & 10,26 & 3,52 \\
\hline
\end{tabular}

A bacia do rio Calhau, conhecida como microbacia do rio Calhau, é de grande importância para a população do Calhau e suas imediações. Suas nascentes estão localizadas a leste da Estação Ecológica do Rangedor, separada apenas pela Avenida Eduardo Magalhães. Essa área, portanto, é considerada como uma Área de Preservação Permanente - APP.

De acordo com o Código Florestal (Lei Federal no 12.727/2012) considera-se Área de Preservação Permanente, em zonas rurais ou urbanas, áreas no entorno das nascentes e dos olhos d'água perenes, qualquer que seja sua situação topográfica, no raio mínimo de 50me . Entretanto, apesar dessa área ser uma APP, percebe-se que muitas nascentes do rio Calhau estão sendo suprimidas pelo avanço da expansão imobiliária ou ainda contaminadas pelo lançamento in natura de esgotos. Vários afluentes desse rio foram assoreados.

Merece destaque a bacia do rio Anil, uma vez que este é um dos maiores rios de São Luís em extensão apresentando $13,8 \mathrm{~km}$, aproximadamente. Suas nascentes estão localizadas no tabuleiro central da Ilha do Maranhão, seguindo para o mar na direção sudeste-noroeste até alcançar a baía de São Marcos. O rio Anil, segundo Feitosa (1990) é considerado um braço de mar, por ter influência marinha.

A bacia do rio Anil é o retrato do descaso do poder público, apresentando em suas margens ocupação irregular, principalmente por palafitas. Essa bacia é altamente antropizada e ameaçada por vários tensores ambientais, inclusive o aterramento de seus mangues para construção civil (shoppings e condomínios residenciais). Ultimamente, essa bacia hidrográfica tem sido alvo de investimentos oriundos do Tesouro Estadual e do Programa de Aceleração do Crescimento (PAC) do Governo Federal para remanejamento, 
saneamento, infraestrutura e construção de apartamentos para as pessoas que foram retiradas de áreas de manguezais localizados na margem esquerda do rio.

Elabore (2006) ressalta que os volumes de água doce retidos na ESEC do Rangedor e respectivos fluxos gerados favorecem a manutenção da corrente do rio Calhau; propiciando também a movimentação de fluxos de água doce para o estuário do rio Anil, no período de estiagem. Esses fatores supracitados vêm reforçar a importância da ESEC do Rangedor na conservação de partes dos afluentes do rio Anil e Calhau, uma vez que estes vêm sendo ameaçados pelo adensamento populacional e consequente impermeabilização dos divisores e vertentes de suas bacias.

Com relação à drenagem da área de estudo, é possível observar na Figura 3 que o padrão de drenagem é do tipo dendrítico. Percebe-se, também, que houve uma perda significativa da drenagem que corta a UC em relação aos anos de 1980 e 2012, conforme se esboça na figura 3. No primeiro período, a área de estudo apresenta uma soma de aproximadamente vinte tributários, enquanto em 2012 houve uma acentuada redução que resultou em apenas nove tributários. Isso está diretamente relacionado com a perda da vegetação e o avanço da expansão urbana.

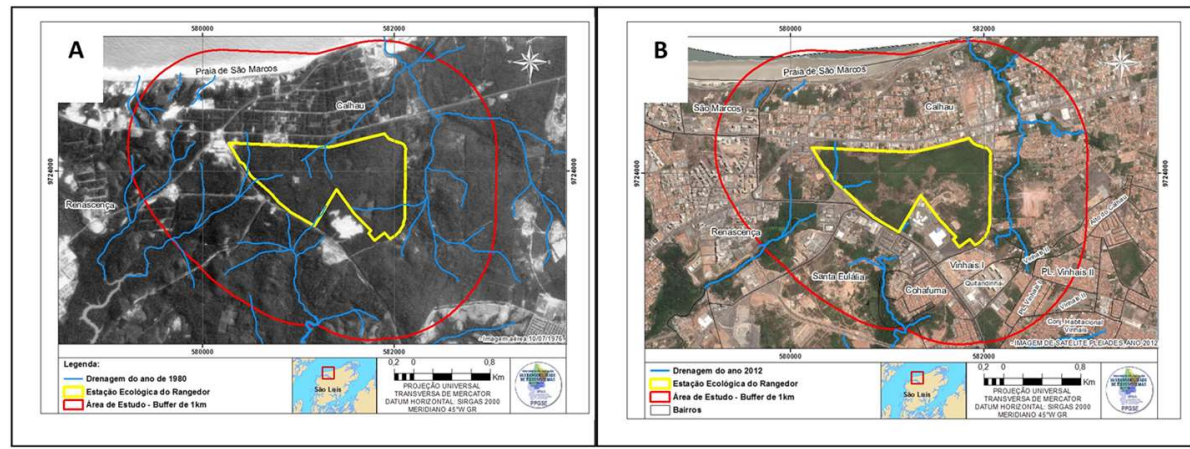

Figura 1: Mapa de drenagem de 1980 (A) e 2012 (B) da ESEC e seu entorno.

Levando em consideração o cálculo da densidade da drenagem (Dd), observou-se que em 1980 (figura 3A), o valor foi de 2,09, reduzindo para 0,97 em 2012, conforme se observa na figura 3B. Os dados observados demonstram que a densidade da drenagem involuiu da categoria média para baixa, diminuindo drasticamente.

Segundo Collares (2000), a rede de drenagem se constitui em um importante indicador de alterações ocorridas na composição da paisagem de bacias hidrográficas, seja por mudanças na sua estruturação, forma, perda ou ganho de canais. Collares (2000) cita ainda alguns fatores físicos que podem influenciar na densidade de drenagem de uma bacia, tais como geologia, topografia, clima, solo, relevo, declividade e vegetação. E como fatores antrópicos, indicam a urbanização e a agricultura como dinamizadores consideráveis na drenagem, fatos estes verificados na ESEC do Rangedor e, principalmente, do seu entorno com a urbanização em ritmo acelerado. Os vetores de pressão identificados com maior potencial de impacto na ESEC foram a presença de resíduos sólidos, a ocorrência da espécie invasora Leucaena leucocephala e o desmatamento na área. 


\section{Presença de resíduos sólidos}

Apesar de a Estação Ecológica do Rangedor estar enquadrada na categoria de Proteção Integral foi observado um total descaso do poder público. A falta de fiscalização é algo facilmente notado, pois a área funciona como um depósito de resíduos sólidos provenientes de lixo doméstico e construção civil (Figuras 4A; 4B e 5). Essa ocorrência se concentra tanto nas bordas quanto no interior da UC.

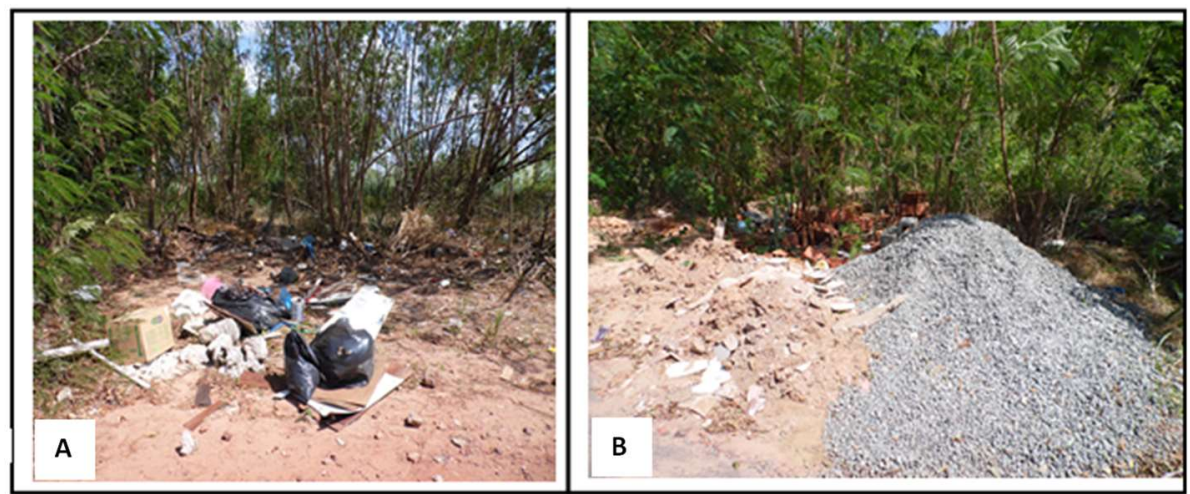

Figura 4: Disposição de resíduos sólidos nas bordas da área da ESEC provenientes de lixo doméstico (A) e construção civil (B).

A Lei Federal no 12.305, de 2 de agosto de 2010, que institui a Política Nacional de Resíduos Sólidos (BRASIL, 2010), conceitua quanto à origem os resíduos da construção civil como aqueles gerados nas construções, reformas, reparos e demolições de obras de construção civil, incluídos os resultantes da preparação e escavação de terrenos para obras civis. De acordo com essa lei, as empresas de construção civil, nos termos do regulamento ou de normas estabelecidas pelos órgãos competentes, estão sujeitas à elaboração de um plano de gerenciamento de seus resíduos sólidos. No entanto, observa-se a que esta prática não faz parte dos costumes das pessoas que depositam os resíduos sólidos de construção civil nas bordas (Figura 4B) e no interior (Figura 5B) da ESEC do Rangedor.

O lixo doméstico, segundo a lei supracitada enquadra-se na categoria resíduos sólidos domiciliares que são aqueles originários de atividades domésticas em residências urbanas. Este tensor foi encontrado em grande quantidade tanto nas bordas (Figura 5A) quanto no interior (Figura 5B) da ESEC do Rangedor, evidenciando assim falta de fiscalização por parte do poder público e falta de sensibilidade ambiental das pessoas que cometem esse ato.

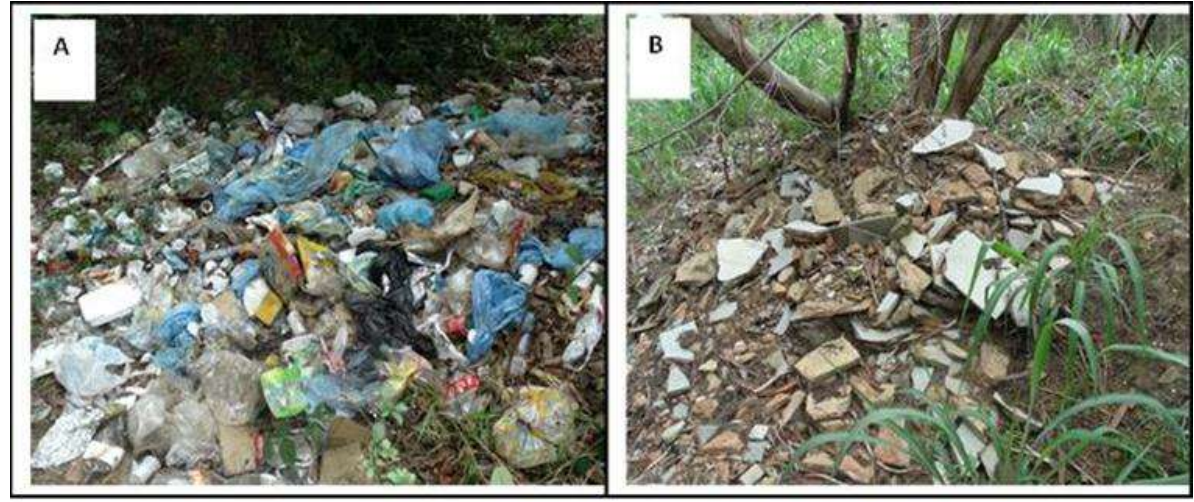

Figura 5: Disposição de resíduos sólidos na borda (A) no interior (B) da área da ESEC. 
Estudos realizados pela Elabore (2006) já destacavam que a grande presença de resíduos sólidos depositado na área, configurava-se como um problema agudo e que deveria ser solucionado, a fim de preservar os recursos naturais da Unidade de Conservação. Entretanto, percebe-se a ausência de qualquer atitude neste sentido, colaborando para que a área protegida funcione permanentemente como um depósito de resíduos sólidos.

Alguns resíduos sólidos encontrados no interior da ESEC demonstram ser bastante antigo, ou seja, algumas embalagens descartadas inadequadamente na área não estão mais disponíveis no mercado. Isso indica que após a implantação desta UC em 2005, nunca foi realizada uma limpeza para retirada do lixo doméstico e dos resíduos de construção civil, incentivando, portanto, práticas ilegais com relação à disposição desses resíduos.

Tambosi (2008), em um estudo realizado na região nordeste de São Paulo, referente à análise de três unidades de conservação, inclusive uma estação ecológica, constatou também o acúmulo de resíduos sólidos tanto nas bordas quanto no interior dessas UCs. Trata-se, então, de uma questão nacional de consciência e sensibilidade ambiental por parte dos autores envolvidos nesse processo. Investi em educação ambiental e fiscalização amenizaria todos esses impactos ambientais que culminam com a contaminação do solo e dos lençóis freáticos, além de atrair vários insetos vetores de doenças.

\section{Espécie invasora Leucaena leucocephala (Lam.)}

Uma planta que chama atenção na paisagem da ESEC do Rangedor é a espécie Leucaena leucocephala, ilustrada na figura 6. Esta é considerada invasora, e está entre as espécies de leguminosas que tem rápido crescimento. É originária da América Central e apresenta ampla distribuição (RESENDE et al., 2001). Esta espécie tem sido muito cultivada devido a uma série de usos múltiplos (LINS, 2007), principalmente para a recuperação da cobertura vegetal e reabilitação de áreas degradadas, por serem fixadora de nitrogênio e ocasionar o enriquecimento do solo.

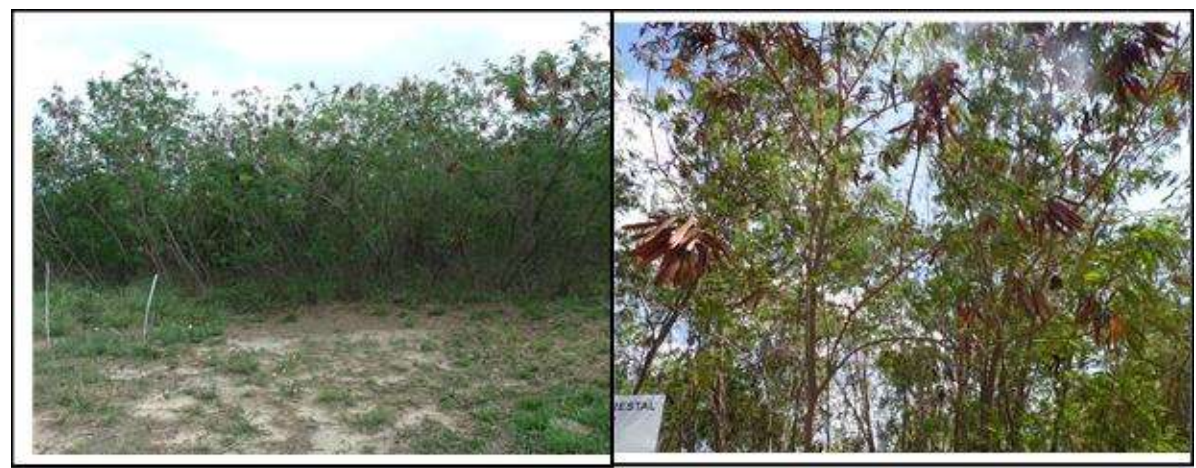

Figura 6: Espécie Leucaena leucocephala (Lam.) de Wit /Leguminosae - Mimosoideae encontrada na ESEC do Rangedor.

Porém, há diversos estudos atribuindo à Leucaena a característica de planta invasora em diversas regiões do mundo (SCHERER, 2005, citado por COSTA et al., 2010), que levaram à sua inclusão na lista das 
100 espécies invasoras mais agressivas do planeta, elaborada pela União Mundial para a Conservação da Natureza - IUCN (LOWE, 2000 citado por COSTA et al., 2010).

O que se percebe é que essa espécie vegetal ocorre de forma agregada e que próximo dela não existem outras plantas, provavelmente devido à liberação de substâncias alelopáticas que inibem o crescimento de outras plantas. Fato observado também por Smith (1985) que afirmam que há relatos de que a espécie pode formar maciços densos, excluindo outras plantas e que, se não for controlada, pode avançar rapidamente sobre áreas adjacentes.

Outro fato importante, é que essa espécie forma grandes populações tanto nas bordas quanto no interior da ESEC, mas preferencialmente em áreas abertas e degradadas, semelhante ao que ocorre com o babaçu (Martinia sp). Neste caso, ela pode ser considerada como uma espécie ruderal, além de invasora, e ainda bioindicadora de áreas degradadas.

\section{Desmatamento na ESEC do Rangedor}

O desmatamento é algo marcante na UC tanto nas bordas quanto no interior. Neste último caso, a ocorrência é atribuída, principalmente, a extração de laterita que acontecia antes na área. A ausência de vegetação no solo contribui significativamente para o desenvolvimento de processos erosivos na área, uma vez que este se encontra desprotegido para enfrentar as intempéries, dificultando a absorção de águas pluviais.

Segundo a Elabore (2006), destaca-se em diversos pontos da ESEC a ocorrência de laterita granular nodular, formando camadas, bolsões ou dispersas em matriz areno-argilosa. A presença das lateritas, ou a associação arenito-laterita é fator de fundamental importância para a estruturação e sustentação do relevo. Em situação de preservação da cobertura vegetal, os processos morfodinâmicos mais atuantes são a infiltração e percolação de água no solo.

Onde a superfície encontra-se à descoberta, predominam processos de erosão, com dissolução e lixiviação de minerais, refletidas na formação de encrostramento no arenito exposto. Pereira (2013) destaca que a presença da cobertura vegetal é de fundamental importância no processo de recepção da água precipitada sobre o solo e que a interceptação desta é feita através da copa das árvores, serrapilheira e das gramíneas.

\section{Proximidade de estradas/avenidas}

Conforme se observa, a ESEC do Rangedor está localizada em uma área totalmente cercada por uma malha viária de fluxo intenso, conforme se nota na figura 7. A construção e manutenção dessas vias gerou diversos impactos como desmatamento produzindo efeito de borda na UC; processos erosivos; facilidade de acesso por pessoas não autorizadas; estacionamento indevido; impermeabilização do solo e aumento de temperatura. 


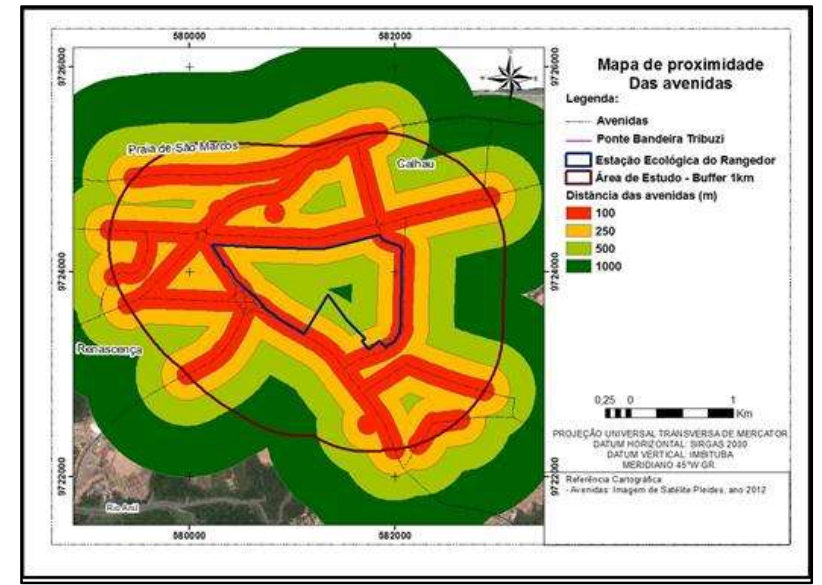

Figura 7. Mapa de proximidade da malha viária em relação aos limites da ESEC do Rangedor.

A fragmentação ambiental nas cidades está associada, principalmente, à proximidade de estradas, então quanto mais próximo destas, maior o impacto no ambiente em questão. Machado (1997) e Berlinck (2008) observaram nas proximidades da Estação Ecológica de Águas Emendadas, no Distrito Federal, a expansão da malha viária e o crescimento das áreas urbanas em direção aos limites da Estação Ecológica, aumentando seu processo de insularização. Fato semelhante ocorre com a estação ecológica do Rangedor.

Um dos impactos gerados pela proximidade de estradas é o desmatamento, pois para a construção destas, precisa-se retirar a cobertura vegetal da área pretendida. Estudos realizados por Porter-Bolland et al. (2007) indicam que as taxas de desmatamento aumentam com a proximidade de estradas. Ferreira (2009) em seus estudos também demonstrou que a proporção do desmatamento como uma função da distância que separa as áreas protegidas das estradas apresenta padrões exponenciais, ou seja, uma grande proporção de desmatamento verificada próximo às estradas e que cai rapidamente com a distância. A construção de estradas também influencia fortemente na impermeabilização do solo e consequentemente no reabastecimento dos lençóis freáticos, uma vez que estas na maioria das vezes, principalmente em áreas urbanas, são asfaltadas impedindo a infiltração das águas pluviais no solo.

\section{Avaliação da efetividade da Estação Ecológica do Rangedor}

Com relação ao uso e cobertura do solo nos três anos estudados (1976, 2001 e 2012), percebeu-se que, mesmo após a implantação da Unidade de Proteção Integral em 2005, a área urbanizada continuou se expandindo tanto no interior da Unidade de Conservação, quanto em seu entorno, delimitado pelo raio de $1 \mathrm{~km}$, lembrando que esta distância está longe de ser a ideal para uma UC inserida nesta categoria. Assim, pode-se dizer que a ESEC do Rangedor não está sendo eficiente neste aspecto.

A falha na efetividade de unidades de conservação é um problema nacional, conforme mostra o estudo realizado pelo WWF-Brasil em parceria com o IBAMA, em 2007. O que ocorre é uma má gestão das UCs, ocasionada por vários fatores. O plano de manejo, por exemplo, que deveria nortear esse gerenciamento é produzido sem seguir, na maioria das vezes, os critérios mínimos para manter a integridade da unidade. No caso, da estação ecológica do Rangedor o plano de manejo não define a zona de amortecimento. Para Vitalli et al. (2009), essa zona deveria funcionar como filtros, impedindo que atividades antrópicas externas coloquem em risco os ecossistemas naturais dentro das áreas protegidas. 
Baseado nas análises das mudanças na densidade de drenagem que intercepta a UC, nos anos de 1980 e 2012, evidencia-se uma perda significativa da drenagem, ocasionando uma densidade bastante reduzida. Este é um dos aspectos mais importante da ESEC, ou seja, a conservação dos rios e seus afluentes torna-se cada vez mais problemática em São Luís devido à expansão da cidade, que gera o soterramento dos mesmos, além do lançamento de esgotos in natura nos corpos d'água. Assim, a criação de Unidades de Proteção Integral deveria ser capaz de conservar esses corpos hídricos, fato que não está acontecendo como mostram os valores de densidade da drenagem dos corpos d'água que interceptam a unidade de conservação.

Quando se identifica os principais tensores que ameaçam a Estação Ecológica do Rangedor observase um total descaso do poder público, facilmente comprovado pela fiscalização ineficiente e pelo acúmulo de resíduos sólidos, principalmente de construção civil. Por outro lado, a presença de muitos indivíduos da espécie vegetal Leucaena leucocephala indica que área está degradada, uma vez que essa planta invasora se adapta muito bem em áreas alteradas. WWF (2007), em sua análise sobre a efetividade de gestão das UCs federais do Brasil, insere esses tensores (disposição de resíduos e presença de espécies exóticas invasoras) no grupo das pressões e ameaças e os define como atividades potencialmente impactantes para essas áreas protegidas.

O estudo supracitado ressalta ainda como atividades fortemente impactantes para as unidades de conservação a construção de infraestrutura e expansão urbana. Esse aspecto poderia ser amenizado na ESEC do Rangedor se existisse em torno da unidade uma zona tampão com o objetivo de amortecer os possíveis impactos gerados pela influência antrópica.

Assim, todos esses impactos gerados na UC e em seu entorno provocam consideravelmente o aumento da temperatura na região, prejudica a infiltração de águas pluviais no solo, afetando a principal função da ESEC do Rangedor que é preservar os recursos hídricos e regular a temperatura da região. Neste sentido, pode-se dizer que a Estação Ecológica não está sendo efetiva na maioria dos objetivos para qual foi criada.

Lima (2005) revelou em sua pesquisa de avaliação da efetividade de manejo das unidades de conservação de proteção integral no estado de Minas Gerais que 23 unidades (60\%) podem ser consideradas 'parques de papel', ou seja, apresentavam nível insatisfatório de manejo, mas em apenas uma unidade esse nível era satisfatório. Além disso, 87\% (34 unidades) não possuíam plano de manejo, nem se encontravam em fase de planejamento.

Aguiar-Silva (2011) também relataram falhas na efetividade de Unidades de Conservação de proteção integral no Ceará apontando que em $81 \%$ das UC não foram utilizados critérios técnico-científicos para determinar a escolha das áreas, tendo como principais motivos pressões político-econômicas. Estes critérios podem ter determinado o cenário atual, onde $75 \%$ das UC estudadas possuem menos que 10.000 ha, enquanto $94 \%$ não possuem plano de manejo e não desenvolvem atividades de monitoramento ambiental. A ausência de planos de manejo pode tornar estas áreas vulneráveis a pressões antrópicas do entorno e interferir na viabilidade e efetividade do Sistema de Áreas Protegidas da região. 


\section{CONCLUSÃO}

A Estação Ecológica do Rangedor não está cumprindo com os critérios mínimos exigidos pela legislação específica para ser enquadrada na categoria de proteção integral. O fato de a ESEC do Rangedor está localizada em um eixo de expansão urbana do município de São Luís, e não possuir uma zona de amortecimento, dificulta o controle da pressão externa sobre a unidade de conservação. Embora revele fortes problemas ambientais observados neste estudo, a existência da ESEC do Rangedor oferece a possibilidade de recuperação da vegetação natural e atua efetivamente contra a ameaça de expansão imobiliária para o interior da área protegida.

\section{REFERÊNCIAS}

AGUIAR-SILVA, F. H.. Avaliação da viabilidade e efetividade das unidades de conservação de proteção integral no Ceará, Brasil. Revista Caatinga, Mossoró, v.24, n.1, p.48-56, 2011.

ARAÚJO, E. P.; JUNIOR, J. W. C. P.; ESPIG, S. A.. Estudo das Unidades de Paisagem da Ilha do Maranhão: delimitação e dinâmica. In: SIMPÓSIO BRASILEIRO DE SENSORIAMENTO REMOTO, 12. Anais. Goiânia: INPE, 2005.

BRASIL. Lei n.6902 de 27 de abril de 1981. Dispõe sobre a criação de Estações Ecológicas, Áreas de Proteção Ambiental e dá outras providências. Brasília: DOU, 1981.

BRASIL. Lei n.9985 de 18 de julho de 2000. Regulamenta o art. 225, § 10, incisos I, II, III e VII da Constituição Federal, institui o Sistema Nacional de Unidades de Conservação da Natureza e dá outras providências. Brasília: DOU, 2000.

BRASIL. Lei n.12305 de 2 de agosto de 2010. Institui a Política Nacional de Resíduos Sólidos; altera a Lei no 9.605, de 12 de fevereiro de 1998; e dá outras providências. Brasília: DOU, 2010.

BRASIL. Lei n.12651 de 25 de maio de 2012. Dispõe sobre a proteção da vegetação nativa; altera as Leis no 6.938, de 31 de agosto de 1981, 9.393, de 19 de dezembro de 1996, e 11.428, de 22 de dezembro de 2006; revoga as Leis no 4.771, de 15 de setembro de 1965, e 7.754, de 14 de abril de 1989, e a Medida Provisória n².166-67, de 24 de agosto de 2001; e dá outras providências. Brasília: DOU, 2012.

COLLARES, E. G. Avaliação de alterações em redes de drenagem de microbacias como subsídio ao zoneamento geoambiental de bacias hidrográficas: aplicação na Bacia Hidrográfica do Rio Capivari -SP. Tese (Doutorado em Geotecnia) - Universidade de São Paulo, São Paulo, 2000.

COSTA, J. N. M. N.; DURIGAN, G.. Leucaena leucocephala (Lam.) de Wit (Fabaceae): invasora ou ruderal?. Revista Árvore, v.34, n.5, p.825-833. 2010.

CHRISTOFOLETTI, A.. Geomorfologia. 2 ed. São Paulo: Blucher, 1980.

ELABORE. Assessoria Estratégica em Meio Ambiente. Plano de manejo da Estação Ecológica do Rangedor. São Luís: ELABORE, 2006.
FEITOSA, A. C.. Controvérsias nas denominações do Anil e Bacanga. Cadernos de Pesquisa, São Luís, v. 6, n.1, p.61-9, 1990.

FRANÇA, G. V.. Interpretação fotográfica de bacias e redes de drenagem aplicada a solos da região de Piracicaba. Tese (Doutorado em Agronomia/Solos e Nutrição de Plantas). Piracicaba, Universidade de São Paulo, 1968.

FERREIRA, L. V.. Unidades de Conservação e Terras Indígenas ajudam a conter desmatamento na Amazônia Brasileira. Estudos Avançados, São Paulo, v.19, n.53, 2009

GUERRA, A. J. T.; MARÇAL, M. D. S.. Geomorfologia Ambiental. Rio de Janeiro: Bertrand, 2006.

HORTON, R. E.. Erosional development of streams and their drainage basins: hidrophysical appoach to quantitative morphology. Geological Society of America Bulletin, Denver, v.56, n.3, p.275-370, 1945.

LIMA, G. S.. Avaliação da efetividade de manejo das unidades de conservação de proteção integral em Minas Gerais. Revista Árvore, v.29, n.4, p.647-653, 2005.

LINS, C. E. L.. Efeito de fungos micorrízicos arbusculares no crescimento de mudas de Leucaena leucocephala (Lam.) de Wit. em solos de caatinga sob impacto de mineração de cobre. Revista Árvore, v.31, n.2, p.355-363, 2007.

LOWE, S.. 100 of the world's worst invasive alien species: a selection from the global invasive species database. Auckland: IUCN, 2000.

MACHADO, R. B.. Um método de análise das áreas de risco no entorno de unidades de conservação: estudo de caso da Estação Ecológica Águas Emendadas, Brasília (DF), Brasil. In: CONGRESSO BRASILEIRO DE UNIDADES DE CONSERVAÇÃO. Anais. Curitiba: Fundação Grupo Boticário, 1997.

MARQUES, A. F.. Novos Parâmetros na Regionalização dos Territórios. Estudo do Zoneamento Ecológico-Econômico (ZEE) na Amazônia Legal e das Bacias Hidrográficas no Rio Grande do Sul (RS). Dissertação (Mestrado em Desenvolvimento Regional) - Santa Cruz do Sul, UNISC, 2006.

NIEL BERLINCK, C.. Diagnóstico socioambiental do entorno da estação ecológica de Águas Emendadas (DF). Tese 
(Doutorado em Ecologia) - Brasília, Universidade de Brasília, 2008.

PORTER-BOLLAND, L.. Land use dynamics and landscape history in La Montaña, Campeche, México. Landscape and Urban Planning, v.2, p.1-10, 2007.

PEREIRA, E. D.. Conflitos de uso na área da Estação Ecológica do Rangedor no município de São Luís (MA). In: ENCONTRO HUMANISTICO, 8. Anais. São Luís: UFMA, 2008.

RESENDE, A. V.; KONDO, M. K.. Leguminosas e recuperação de áreas degradadas. Informe Agropecuário, v.22, n.210, p.46-56. 2001.

SANTOS, R. M.. Padrão temporal e espacial das mudanças de usos da terra e cenários para a conservação da biodiversidade regional do município de São Félix do Araguaia, MT. Tese (Doutorado) - Universidade Federal de São Carlos, São Carlos, 2011.

SANTOS, J. N.; PEREIRA, E. D.. Carta de susceptibilidade a infiltração da água no solo na sub-bacia do rio Maracanã MA. Caderno de Pesquisa, v.20, p.63-71, 2013.

SCHERER, L. M.. Allellopatic effects of aqueous extracts of leucena (Leucaena leucocephala Wit) leave and fruit on germination and root growth of canafístula (Peltophorum dubium Spreng). Ciências Biológicas e Saúde, v.26, n.2, p.161-166, 2005.
SMITH, C. W.. Impact of alien plants on Hawai'i's native biota.. In: STONE, C. P. J.; SCOTT, M.. Hawaii'i's Terrestrial Ecosystems: Preservation and Management. Honolulu: University of Hawaii, 1985. p.180-250.

SOUZA, B. B. G.. Caracterização de indicadores sócioambientais na bacia do rio Anil, São Luís - MA como subsídio à análise econômico-ambiental do processo de desenvolvimento. Tese (Doutorado em Geociências) Universidade Federal Fluminense, Niterói, 2005.

TAMBOSI, L. R.. Análise da paisagem no entorno de três unidades de conservação: subsídios para a criação da zona de amortecimento. Dissertação (Mestrado em Ciências) Universidade de São Paulo, São Paulo, 2008.

TORRES-GÓMEZ, M.. Estructura del paisaje a lo largo de gradientes urbano-rurales en La cuenca del río Aisén (Región de Aisén, Chile). Revista Chilena de Historia Natural, v.82, p.73-82, 2009.

VITALLI, P. L.; DURIGAN, M. J. B.. Considerações sobre a legislação correlata à zona-tampão de unidades de conservação no Brasil. Ambiente \& Sociedade, v.12, n.1. p.67-82, 2009.

WWF. World Wide Fund for Nature. Efetividade de Gestão das Unidades de Conservação Federais do Brasil: Implementação do Método Rappam: Avaliação Rápida e Priorização da Gestão de Unidades de Conservação. Brasília: WWF, 2007. 